University of Nebraska - Lincoln

DigitalCommons@University of Nebraska - Lincoln

USDA National Wildlife Research Center - Staff Publications
U.S. Department of Agriculture: Animal and Plant Health Inspection Service

October 2007

\title{
Effects of Coyote Population Reduction on Swift Fox Demographics in Southeastern Colorado
}

\author{
Seija M. Karki \\ Utah State University, Logan, UT \\ Eric M. Gese \\ Utah State University, eric.gese@usu.edu \\ Mead L. Klavetter \\ Utah State University, Logan, UT
}

Follow this and additional works at: https://digitalcommons.unl.edu/icwdm_usdanwrc

Part of the Environmental Sciences Commons

Karki, Seija M.; Gese, Eric M.; and Klavetter, Mead L., "Effects of Coyote Population Reduction on Swift Fox Demographics in Southeastern Colorado" (2007). USDA National Wildlife Research Center - Staff Publications. 700.

https://digitalcommons.unl.edu/icwdm_usdanwrc/700

This Article is brought to you for free and open access by the U.S. Department of Agriculture: Animal and Plant Health Inspection Service at DigitalCommons@University of Nebraska - Lincoln. It has been accepted for inclusion in USDA National Wildlife Research Center - Staff Publications by an authorized administrator of DigitalCommons@University of Nebraska - Lincoln. 


\title{
Effects of Coyote Population Reduction on Swift Fox Demographics in Southeastern Colorado
}

\author{
SEIJA M. KARKI, Department of Wildland Resources, Utah State University, Logan, UT 84322-5230, USA \\ ERIC M. GESE, ${ }^{1}$ United States Department of Agriculture, Wildlife Services, National Wildife Research Center, Department of Wildland Resources, \\ Utah State University, Logan, UT 84322-5230, USA \\ MEAD L. KLAVETTER, ${ }^{2}$ Department of Wildland Resources, Utah State University, Logan, UT 84322-5230, USA
}

\begin{abstract}
The distribution and abundance of swift foxes (Vulpes velox) has declined from historic levels. Causes for the decline include habitat loss and fragmentation, incidental poisoning, changing land use practices, trapping, and predation by other carnivores. Coyotes (Canis latrans) overlap the geographical distribution of swift foxes, compete for similar resources, and are a significant source of mortality amongst many swift fox populations. Current swift fox conservation and management plans to bolster declining or recovering fox populations may include coyote population reduction to decrease predation. However, the role of coyote predation in swift fox population dynamics is not wellunderstood. To better understand the interactions of swift foxes and coyotes, we compared swift fox population demographics (survival rates, dispersal rates, reproduction, density) between areas with and without coyote population reduction. On the Piñon Canyon Maneuver Site, Colorado, USA, we monitored 141 swift foxes for 65,226 radio-days from 15 December 1998 to 14 December 2000 with 18,035 total telemetry locations collected. Juvenile swift fox survival rate was increased and survival was temporarily prolonged in the coyote removal area. Adult fox survival patterns were also altered by coyote removal, but only following late-summer coyote removals and, again, only temporarily. Coyote predation remained the main cause of juvenile and adult fox mortality in both areas. The increase in juvenile fox survival in the coyote removal area resulted in a compensatory increase in the juvenile dispersal rate and an earlier pulse in dispersal movements. Adult fox dispersal rate was more consistent throughout the year in the coyote removal area. Coyote removal did not influence the reproductive parameters of the swift foxes. Even though juvenile survival increased, swift fox density remained similar between the areas due to the compensatory dispersal rate among juvenile foxes. We concluded that the swift fox population in the area was saturated. Although coyote predation appeared additive in the juvenile cohort, it was compensatory with dispersal. (JOURNAL OF WILDLIFE MANAGEMENT 71(8):2707-2718; 2007)
\end{abstract}

DOI: $10.2193 / 2006-275$

KEY WORDS Canis latrans, coyote, dispersal, predation, reproduction, survival, swift fox, Vulpes velox.

Studies have shown many examples of competition between sympatric canids (Johnson et al. 1996), the mechanisms for coexistence, and the various interactions observed and their possible interpretations (e.g., Fuller and Keith 1981, Voigt and Earle 1983, Sargeant et al. 1987). Thurber et al. (1992) found where coyote (Canis latrans) and wolf (C. lupus) home ranges overlapped, interference competition may have caused differing abundances, but little dietary overlap and minimal exploitation competition allowed for coexistence. Theberge and Wedeles (1989) found when primary prey was low, red foxes $(V$. vulpes) turned to alternate prey, whereas coyotes differed in their location of foraging and they concluded that balanced competitive abilities allowed for coexistence. Harrison et al. (1989) found red foxes established home ranges outside or between coyote territories and had different use patterns in areas of overlap. They surmised that red foxes coexisted with coyotes because of smaller spatial requirements.

The swift fox (Vulpes velox) is one of North America's smallest canids. Native to mid- and short-grass prairies of the central regions of North America, historically swift foxes ranged from the Canadian prairies through Montana and the Dakotas, and south to eastern New Mexico and Texas, USA (Scott-Brown et al. 1987). Once abundant throughout

${ }^{1}$ E-mail: egese@cc.usu.edu

2 Present address: Directorate of Environmental Compliance and Management, United States Army Piñon Canyon Maneuver Site, 36086 Highway 350, Model, CO 81059, USA their range, swift foxes suffered a decline during the late 19th and early 20th centuries. Reasons for the decline include changing grazing patterns, fire suppression, trapping, ecological changes associated with the extirpation of wolves, hunting, incidental poisoning, dogs (C. familiaris), and habitat fragmentation and loss associated with the westward expansion of humans (Hillman and Sharps 1978, Egoscue 1979, Scott-Brown et al. 1987). The swift fox has since made a slight comeback (Carbyn 1998), yet is found in only $40 \%$ of its former range in the United States.

The coyote is a mid-sized canid that competes with swift foxes for food and space (Kitchen et al. 1999). Diet includes lagomorphs, small mammals, birds, insects, vegetation, fruits and berries, carrion, livestock, and native ungulates (Voigt and Berg 1987, Kitchen et al. 1999). Once centralized in the western States, the coyote has expanded its range to include most of North America (Bekoff and Gese 2003). Although historically the focus of large-scale control efforts (Wagner 1975, Andelt 1987), coyotes appear to be highly adaptive and flourishing (Bekoff and Gese 2003).

The general consensus from several studies is that predation by coyotes is one of the leading causes of mortality in swift fox populations (e.g., Covell 1992, Sovada et al. 1998, Schauster et al. 2002a). Coyote removal is often suggested as a method for increasing swift fox populations, especially in times of stress (i.e., resource decline or reintroduction; Carbyn 1998, Kamler et al. 2003a). Experimentally manipulating predator numbers can lead to 
insights regarding the effects of a larger carnivore on a smaller, competing carnivore species (Holt and Polis 1997, Henke and Bryant 1999, Terborgh et al. 1999). The intent of coyote removal as a management tool is to increase the swift fox population by increasing survival, juvenile recruitment, and population density. In areas seeking recovery of swift foxes, an increase in population level and colonization of new areas would be desired results. With continued concern for swift fox conservation and population recovery, investigations of the factors influencing swift fox population dynamics and the role of coyote predation in swift fox population ecology is paramount.

We conducted a large-scale removal of coyotes to investigate the effects of coyote population reduction on swift fox demographics with the primary intent to examine if we could influence swift fox survival and density. We tested whether reducing coyote density would change swift fox demographics, in particular survival rates, dispersal rates, density, and reproduction. If no overall increase in swift fox density is observed, then predation may not be the crucial factor, but is compensatory, and predator removal may not be effective for increasing swift fox population size.

\section{STUDY AREA}

We conducted our study on the $1,040-\mathrm{km}^{2}$ Piñon Canyon Maneuver Site (PCMS), Las Animas County, Colorado, USA. The regional climate was classified as semiarid with a mean annual precipitation of $26-38 \mathrm{~cm}$ and mean monthly temperatures ranging from $-1^{\circ} \mathrm{C}$ in January to $23^{\circ} \mathrm{C}$ in July (Shaw and Diersing 1990). The topography included an extensive sandstone river canyon system along the eastern boundary, basalt outcroppings along the southern perimeter, open plains in the central portion, and rolling hills and limestone breaks to the north and west. Elevation across the site ranged from $1,310 \mathrm{~m}$ to $1,740 \mathrm{~m}$. The associated vegetation types included shortgrass prairie, shrub-grasslands, and woodlands of pinyon pine (Pinus edulis) and oneseed juniper (Juniperus monosperma). The PCMS was purchased in 1982 for military training 3-4 times a year. Prior to purchase, the area was managed for cattle and sheep grazing during which time predators were subjected to hunting and trapping. From 1988 to 1997 limited coyote hunting occurred on the site. From 1997 to 1998 the site was again restricted from any coyote hunting until initiation of removals in 1999 for this study.

\section{METHODS}

\section{Study Design}

We separated the study area into 2 treatment areas: a 230$\mathrm{km}^{2}$ area where we removed coyotes and a $145-\mathrm{km}^{2}$ area with no coyote removal. From baseline data collected during the 2 years prior to coyote removal (Kitchen et al. 1999, Schauster et al. 2002a), the 2 treatment areas were considered similar in swift fox density, habitat, prey base, and coyote density. The topography of both areas consisted mostly of prairie with a few hills and canyons along the boundaries. Shortgrass prairie was the dominant vegetation and was considered similar between the areas. Military use was comparable between the areas. Both areas were bordered to some extent by private ranches. The border between the areas was based on previously known coyote home ranges (Kitchen et al. 1999). We selected 2 areas instead of randomly selecting animals because of the logistics involved in coyote removal and the overlapping home ranges between and among swift foxes and coyotes (Kitchen et al. 1999).

We attempted to radiocollar all swift foxes within each area. We sampled swift foxes seasonally along transects, with supplemental trapping at dens. We considered each area, fox, and fox social unit as independent. We realized other factors (e.g., age, sex, season, yr) would influence tests for treatment effects and we considered these factors in the analyses. We classified foxes as either adults or juveniles. Since juveniles may breed their first year (Scott-Brown et al. 1987), we considered juveniles as adults their first breeding and gestation season or on 1 January. We divided each year into 3 seasons according to swift fox behavior: breeding and gestation (15 Dec-14 Apr), pup-rearing (15 Apr-14 Aug), and dispersal (15 Aug-14 Dec). We used the program SYSTAT (Wilkinson et al. 1992) for all inferential statistics. Due to large sample sizes, we assumed normality and we used pooled variances in all $t$-tests and $z$-tests.

\section{Coyote Removal}

We conducted coyote removals twice a year in the removal area. We timed removal to occur prior to peaks in swift fox mortality during the breeding (Feb-Mar) and dispersal (Aug) seasons as determined by Schauster et al. (2002a); we captured and radiocollared swift foxes throughout the year. We removed coyotes in late winter when coyote populations were at their lowest level and represent the resident breeding population, and prior to whelping to remove the parent plus potential offspring, thereby prolonging the removal effect (Knowlton 1972, Gese et al. 1989a). If immigration did occur as a result, it would be too late to contribute to the reproductive effort. In late summer, we removed coyotes to reduce their density and minimize encounters with juvenile swift foxes during dispersal. We removed coyotes using aerial gunning from a helicopter for 2-3 consecutive days during dawn hours, or where and when coyotes appeared most active (Gese et al. 1989b, Kitchen et al. 2000). We employed aerial gunning based on target specificity, efficiency, and public acceptability (Arthur 1981, Cypher and Scrivner 1992). Aerial gunning also reduces learned avoidance behaviors by coyotes (Sacks et al. 1999). We removed as many coyotes as possible in the time allotted.

We measured the level of coyote population reduction by 2 independent methods. The first estimate made use of the radioed coyotes present in the study area (Kitchen et al. 1999) with the number of radioed animals removed providing an estimate of the percent of the population removed. Second, we estimated the level of the coyote population removed during removal sessions by calculating the percent removed given an estimate of how many coyotes the removal area would potentially hold. We corrected mean seasonal group sizes to mean seasonal pack sizes by adding a 
percentage for those animals not observed (Gese et al. 1988, 1989a). We used corresponding seasonal coyote home-range sizes from Kitchen et al. (1999) to calculate seasonal densities. Given densities and removal area size, we calculated the number of resident coyotes and subsequently corrected this number by including a percentage for transient coyotes (Gese et al. 1989a, Kitchen et al. 1999) to achieve total coyote population estimates of the removal area. We then calculated percentages of the coyote population removed for each removal session.

\section{Swift Fox Capture and Radiotelemetry}

We used $80 \times 25 \times 25-\mathrm{cm}$ box traps (Tomahawk Live Trap Co., Tomahawk, WI) baited with chicken, sardines, or vehicle-killed leporids to capture and radiocollar swift foxes. We placed traps along transects, roads, or at dens. For recollaring or replacing malfunctioning transmitters, we employed an enclosure system (Kozlowski et al. 2003). We set each trap at dusk and checked them at dawn for 4 consecutive nights during surveys or until we accomplished specific captures. We closed traps each morning and reopened them in the evening, or closed them during inclement weather (e.g., heavy precipitation, wind, extreme cold). Upon capture, we weighed, sexed, aged by tooth wear, ear-tagged, and fitted each fox with a 30-50-g radiotransmitter equipped with a mortality sensor (Advanced Telemetry Systems, Isanti, MN). We released each fox at their capture site. We did not trap juveniles until late in the pup-rearing or early dispersal season (Jul-Aug) when they had achieved sufficient growth to be radioed and prior to dispersal. Hence, we did not include juveniles in the study during the breeding and gestation season and most of the pup-rearing season. All animal capture and handling protocols were approved by the Institutional Animal Care and Use Committees (IACUC) at the National Wildlife Research Center (QA-472) and Utah State University (IACUC No. 841).

We located radioed swift foxes 1-2 times daily. During the day, we located each fox either visually or by identifying a den with the animal inside. During the night, we located swift foxes by triangulation, with animal-locating sessions separated by 4-8 hours to maintain independence of locations (Swihart and Slade 1985, Otis and White 1999). Triangulation consisted of 2-3 compass bearings from known locations within 10 minutes with intersecting angles of $20-160^{\circ}$. We then plotted each location and determined Universal Transverse Mercator grid locations using program Locate II (Pacer; Truro, Nova Scotia, Canada). We checked telemetry error periodically with reference transmitters. Our goal was approximately 60 locations distributed over 24 hours each season (4 months) per animal for home range analysis (Gese et al. 1990).

\section{Survival Rates and Cause-Specific Mortality}

Mortality sensors within transmitters activated if no movement was detected in 4-6 hours. Upon detecting a mortality signal, we recovered the transmitter and remains of the swift fox immediately. We recorded the location of carcass using a
Global Positioning System unit, searched the area for tracks, sign, scavenging, evidence of cause of death, and collected any remains. A necropsy ensued to determine cause of death (Disney and Spiegel 1992). If we did not observe any gross trauma, we sent animals to the Wyoming State Veterinary Laboratory (Laramie, WY) for analysis.

We calculated monthly survival rates for January 1999 through December 2000 using the program MICROMORT followed by $z$-tests to determine differences between individual monthly survival rates between the 2 treatment areas (Heisey and Fuller 1985). We used monthly survival rates instead of annual or seasonal rates in order to detect changes on a finer time scale and assess effects closer to the coyote removal dates. We divided the age groups (ad, juv) for analysis and monitored them for differing time periods. Survival analyses only included swift foxes with known fates (White and Garrott 1990, Murray 2006) and assumed they represented a random sample of the population (Pollock et al. 1989, Winterstein et al. 2001).

\section{Dispersal Rates, Distance, and Success}

We considered a juvenile swift fox to have dispersed if it established a distinct home range separate from its natal range (spatially), or separated from parental care as determined by date and was no longer located in the same den at the same time as their parents (temporally). An adult swift fox dispersed if it established a distinct home range separate from its previous home range, possibly as a result of the death of a mate, appearance of a new dominant fox, or separation from an existing social unit. Dispersal started on the last day in its previous home range, and ended on the first day in a new home range or when it stopped returning to the natal or previously used area. We examined dispersal patterns of foxes in terms of number, sex, age, rate, timing, and outcome (Scrivner et al. 1987). For each age cohort, we calculated monthly dispersal rates $(1$ - residency rates) similar to survival rates for January 1999 through December 2000 within each treatment area using MICROMORT, substituting dispersals for deaths (Fuller 1989). We conducted separate $z$-tests to determine differences between monthly dispersal rates between the 2 areas (Heisey and Fuller 1985). We performed a chi-square test to determine if there was an association of treatment area and fox age with dispersal outcome.

\section{Reproduction}

We began den watches in late May or when we observed the first pup outside the den (Scott-Brown et al. 1987). Covell (1992) determined the average whelping date on the PCMS as 21 April. We ceased den watches when litters began to separate and pups inhabited different dens daily (late Jul). A den watch required an observer to locate the parents at a den by telemetry or to visit a known natal den and observe the number of pups for 2 hours during dawn or dusk. Binoculars and spotting scopes enabled viewing from a distance. We assumed no modification in behavior affecting litter counts occurred based on the foxes' unwary and curious demeanor toward humans (Cutter 1958, Egoscue 1979). We identified 
natal dens by the greater $(\geq 4)$ than usual (1-3) number of entrances, trampled vegetation about the den entrance, pup tracks, prey items, and small-sized scat at den entrances (Kilgore 1969, von Schantz 1984). Watches revealed the reproductive status (breeding and success) of individual social units, social structure, and facilitated radiocollaring of juveniles. We used reproduction (\% success and litter size) per social unit in the analyses. We performed chi-square tests to test for an association between social unit reproduction estimates and area and year. We used the highest litter count observed within each social unit each month to determine average monthly, postwhelping litter size for each area and year. We used a multi-way analysis of variance (ANOVA) to test for influences of area and year, and their interactions, on swift fox litter size. When we found significance, we used 2-sample $t$-tests to determine the differences within variables.

\section{Population Estimates}

We used 2 independent methods to estimate swift fox population size and the response to coyote population reduction. First, to determine swift fox density, we calculated seasonal home-range sizes of social units. Since swift fox dynamics in the vicinity of transects changed throughout a season (due to birth, death, dispersal), we used social units because they were more consistent and would be more representative of the resident population. We considered foxes as part of a social unit for a season if their home ranges overlapped, frequently and concurrently used the same dens, and if an individual was tracked in that area for more than half the biological season (ad), or was collared late in the season (less than half), but was identified to be from that social unit and did not disperse before half the season had passed (juv). During the puprearing season, we included all offspring identified during den watches in the total number for each social unit, assuming juveniles were too young to disperse until at least halfway through the pup-rearing season (Hillman and Sharps 1978, Covell 1992). We determined home-range size for each social unit using all the locations for the social unit (White and Ralls 1993, White et al. 1994). We calculated home-range sizes using the $95 \%$ isopleth of the Adaptive Kernel Method (Worton 1989) using CALHOME (Kie et al. 1996). With ARCVIEW 3.2 we plotted home ranges in relation to survey transects (Schauster et al. $2002 a, b)$. If the home range touched a transect, we included it in further analysis. Transects were buffered by the radius of the average home-range size (of those touching the transect) to calculate an area estimate of available habitat along the transect (Schauster et al. 2002a, $b)$. We added the area of the included home ranges beyond the buffer to the transect area to obtain a total estimate of used and available habitat (Schauster et al. 2002a, b). We then calculated seasonal densities for each year and transect as the total number of foxes per total area. To test if swift fox density responded to changes in coyote density we used a multi-way ANOVA to examine the influence of area, and also, season and year on swift fox density estimates (main effects only), because fox density may fluctuate seasonally or annually. We used an independent 2-sample $t$-test to determine if there was a difference in fox density between the areas.

Our second method of determining swift fox population size used mark-recapture estimates from trapping surveys (Schauster et al. 2002a, b). Trapping surveys required placing a baited box trap every $0.5 \mathrm{~km}$ along 5 10-km transects for 4 consecutive nights. We processed foxes as previously described. We similarly checked and shut traps each morning and reopened them in the evening. We used mark-recapture estimates because it provided the best predictor of swift fox density (Schauster et al. 2002b). We calculated mark-recapture estimates using the Schnabel method (Schnabel 1938): $N=\Sigma\left(C_{t} M_{t}\right) / \Sigma R_{t}$, where $M=$ number of foxes available or marked prior to sampling, $C=$ number of foxes captured, $R=$ number of recaptures. Initial available foxes were radioed individuals that occupied a home range that intersected the transect prior to the survey date during that season (Schauster et al. 2002a, b). We did not consider missing animals to be available unless we recaptured them during surveys with a faulty collar in the same area they were using prior to being classified as missing. Animals that we recaptured during the surveys, but had home ranges that did not appear to intersect a transect, we also considered available. We used a multi-way ANOVA to test for influences of area, season, and year with main effects only. If we found a significant factor, we performed an independent 2-sample $t$-test to test for differences.

\section{RESULTS}

\section{Coyote Removal}

We removed 124 coyotes during 4 removal sessions (18-20 Mar 1999, 18-19 Aug 1999, 15-16 Feb 2000, 8-10 Aug 2000). During the first removal session, we removed 6 of 10 $(60 \%)$ radiocollared coyotes from a previous study (Kitchen et al. 1999) known to be in the removal area. We assumed similar removal results (approx. 60\%) for all sessions, because we spaced the removals months apart (Gese 2005), we removed all coyotes chased, and the low occurrence of other helicopter disturbance should have reduced any learned avoidance. Seasonal percentages of removal based on coyote group size, density, and removal area size ranged from $40.5 \%$ to $75.0 \%$ with a mean of $59.7 \%$ (Table 1 ), similar to the previous estimate using the radioed sample $(60 \%)$.

\section{Swift Fox Captures}

We captured 110 new foxes between 15 December 1998 and 14 December 2000, marking 96 with radiocollars and ear tags, and 13 with ear tags only; 1 fox in a trap was killed by coyotes. We also monitored 45 foxes previously collared in 1997-1998 (Schauster et al. 2002a) for 141 total radioed foxes monitored for 65,226 radio-days. The removal area had 88 (49 M:39 F) foxes, and the nonremoval area had 53 (24 M:29 F) foxes based on the area at capture or home range prior to the start of this study. We collected 18,035 radiotelemetry locations on the 141 foxes. 
Table 1. Estimates of the percentage of the coyote population killed during 4 removal sessions, Piñon Canyon Maneuver Site, Colorado, USA, 1999-2000.

\begin{tabular}{|c|c|c|c|c|c|c|c|c|}
\hline $\begin{array}{l}\text { Removal } \\
\text { session }\end{array}$ & $\begin{array}{c}\text { Home-range } \\
\text { size }\left(\mathrm{km}^{2}\right)\end{array}$ & $\begin{array}{l}\text { Group } \\
\text { size }\end{array}$ & $\begin{array}{l}\text { Pack } \\
\text { size }\end{array}$ & $\begin{array}{c}\text { Density } \\
\left(\text { coyotes } / \mathrm{km}^{2}\right)\end{array}$ & $\begin{array}{c}\text { No. } \\
\text { residents }\end{array}$ & $\begin{array}{l}\text { No. } \\
\text { coyotes }\end{array}$ & $\begin{array}{c}\text { No. } \\
\text { removed }\end{array}$ & $\begin{array}{c}\% \\
\text { removed }\end{array}$ \\
\hline 1 & 17.7 & 3.3 & 4.5 & 0.25 & 58 & 61 & 45 & 74.0 \\
\hline 2 & 17.3 & 2.3 & 3.8 & 0.22 & 50 & 53 & 26 & 49.4 \\
\hline 3 & 17.7 & 2.1 & 2.8 & 0.16 & 37 & 39 & 29 & 75.0 \\
\hline 4 & 16.7 & 2.5 & 4.1 & 0.25 & 56 & 59 & 24 & 40.5 \\
\hline
\end{tabular}

\section{Survival Rates and Cause-Specific Mortality}

Removing coyotes altered juvenile survival rates and had a smaller influence on adult survival rates (Fig. 1). In general, mean monthly survival rates were higher where coyotes were removed. Adult swift foxes showed a significant increase in survival rates in the removal area during 3 of 24 months monitored (Fig. 1A). During the 3 months of significant increases, adult survival rates increased a mean of $10.5 \%$ monthly (range $=8.9-11.5 \%$ ) in the removal area compared to the nonremoval area, while the other 21 months showed a mean change of only $3.4 \%$ monthly (range $=0.0-7.9 \%$ ). Adult survival rates remained higher, temporarily, following summer removals into the autumn dispersal season. The largest effect of coyote removal, however, was increased juvenile swift fox survival (Fig. 1B). Juveniles had significantly higher survival rates during 3 of 10 months monitored and lived a few months longer in the removal area compared to juveniles in the nonremoval area (Fig. 1B). During those 3 months, juvenile survival rates increased a mean of $27.9 \%$ monthly (range $=12.6-52.4 \%$ ) in the removal area compared to the nonremoval area, whereas the remaining 7 months showed a mean change of only $3.1 \%$ monthly (range $=0.0-11.0 \%$ ). The trends for juveniles in both areas were similar, yet survival rates for foxes in the

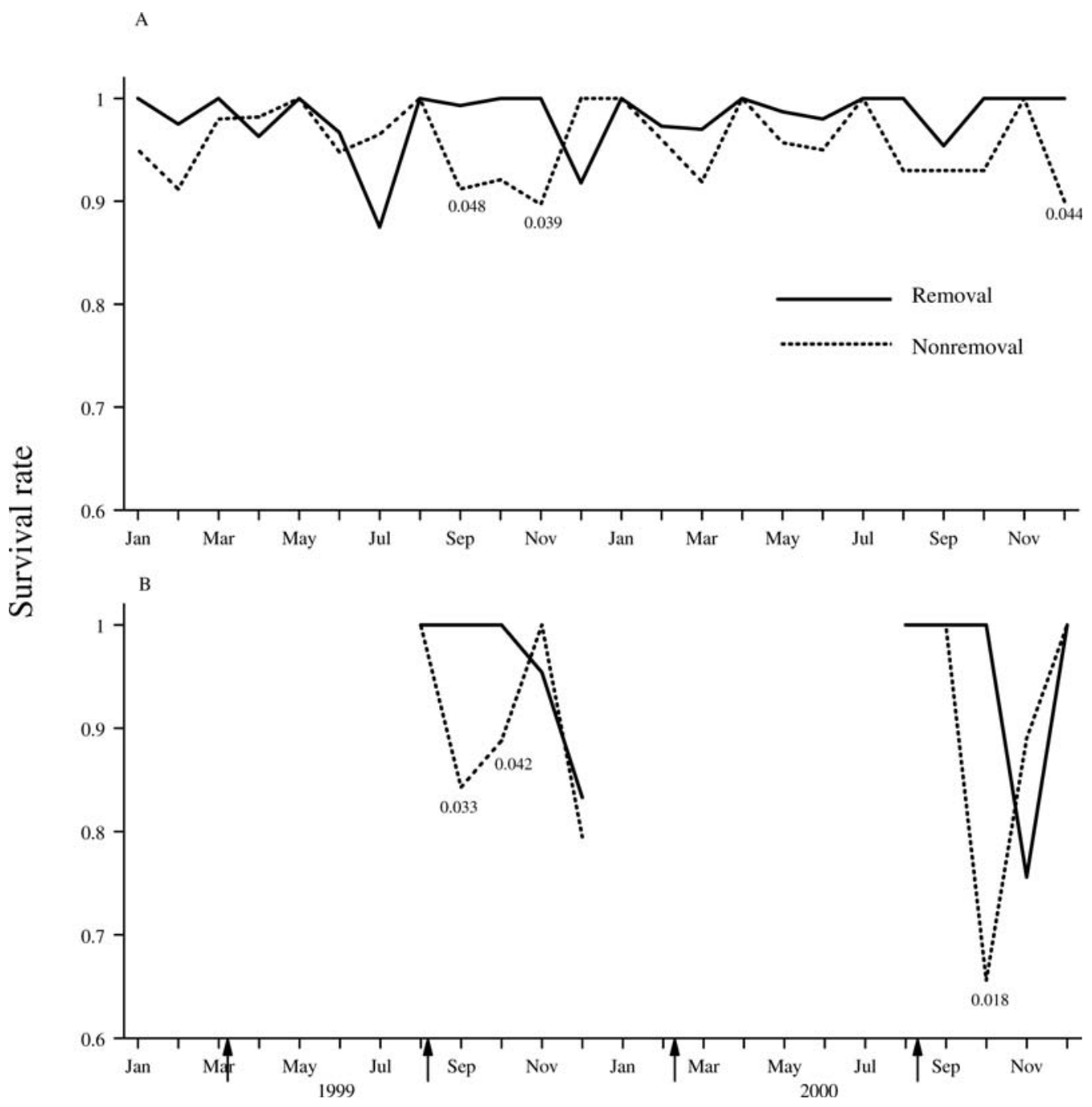

Figure 1. Monthly survival rates for (A) adult and (B) juvenile swift foxes in the removal and nonremoval areas, Piñon Canyon Maneuver Site, Colorado, USA, 1999-2000. $P$-values indicate a significant difference between the monthly survival rates as determined by a $z$-test. Arrows indicate time of coyote removals. 


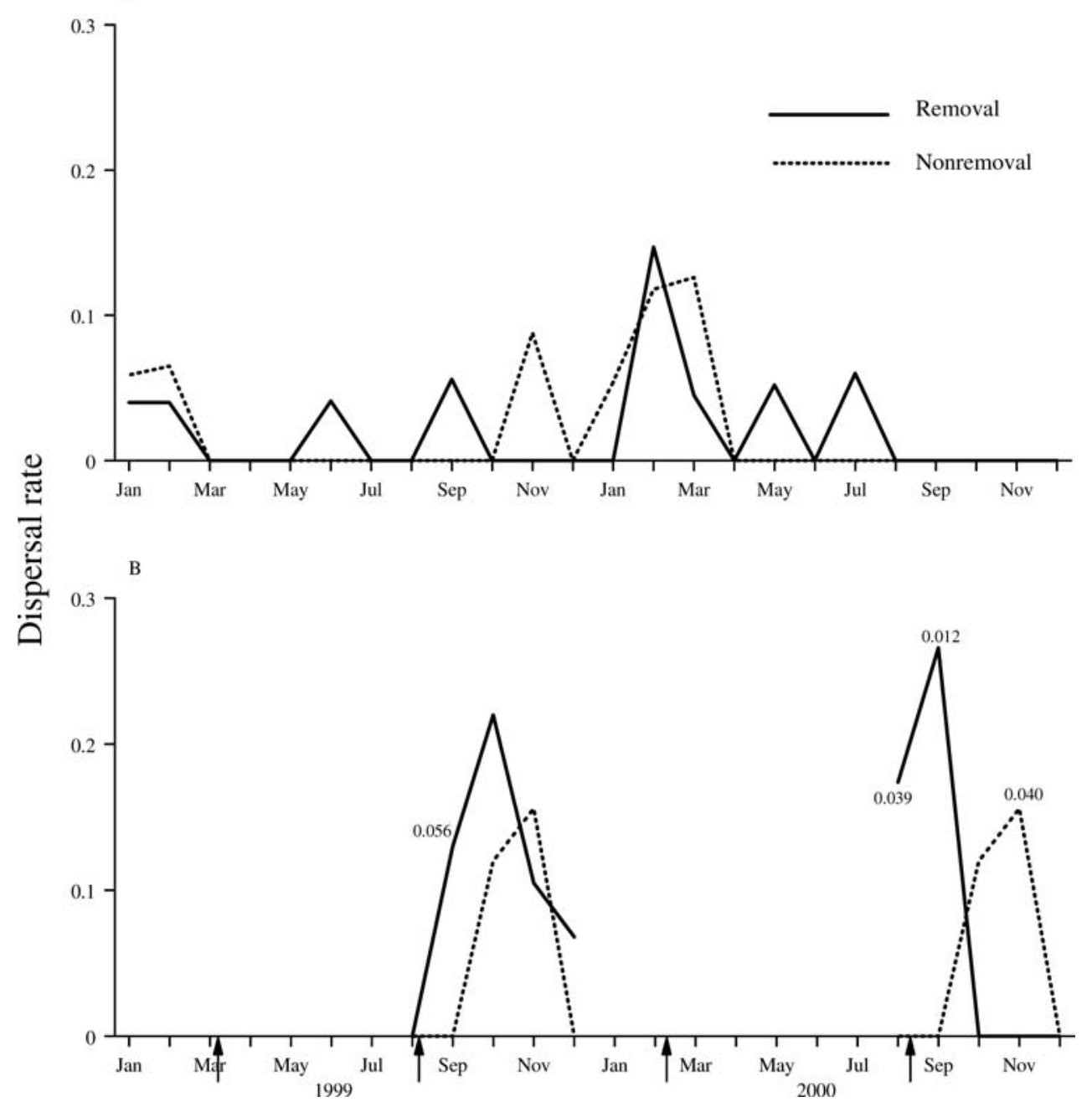

Figure 2. Monthly dispersal rates for (A) adult and (B) juvenile swift foxes in the removal and nonremoval areas, Piñon Canyon Maneuver Site, Colorado, USA, 1999-2000. $P$-values indicate a significant difference between the monthly dispersal rates as determined by a $z$-test. Arrows indicate time of coyote removals.

removal area shifted to the right (i.e., were delayed) and fluctuations were not as severe. Survival for juveniles increased immediately following summer coyote removals. Unfortunately, the effect was not sustained, because survival rates were similar for both areas by the breeding and gestation season.

Although survival increased (mostly in the juv cohort), 61 foxes died during the study. We recovered 30 mortalities in the removal area and we recovered 31 mortalities in the nonremoval area. Predation accounted for 44 of these deaths with 29 attributed to coyotes. Of the 29 foxes known to have been killed by coyotes, $18(62 \%)$ were in the removal area and $11(38 \%)$ in the nonremoval area.

\section{Dispersal Rates and Success}

During the course of the study, 36 (19 M:17 F) foxes dispersed. We found 38 dispersal movements occurred with 21 movements by adults and 17 by juveniles. We documented 10 foxes dispersed from the removal area into the nonremoval area, whereas only 2 foxes dispersed from the nonremoval area into the removal area. In addition, 15 foxes dispersed within the removal area, whereas 11 foxes moved within the nonremoval area. With increased survival rates of juvenile foxes following coyote removal, dispersal rates also changed. Mean monthly dispersal rates for adult swift foxes did not differ between the removal and nonremoval areas (Fig. 2A). In contrast, monthly dispersal rates among juvenile foxes were different between treatment areas during 4 of 10 months monitored; we considered the alpha level of 0.056 for September 1999 to be a significant effect and biologically relevant (all other $z$-tests had $P$ values $>0.1$ ). Juvenile dispersal in the removal area occurred at a higher rate and earlier as compared to juvenile foxes in the nonremoval area (Fig. 2B). The magnitude of change showed that juvenile foxes in the removal area increased dispersal rates a mean of $24.1 \%$ monthly (range $=14.9$ $36.2 \%$ ) compared to juveniles in the nonremoval area. In contrast, juvenile foxes in the nonremoval area increased their dispersal rate by $18.5 \%$ in November 2000 when compared to juveniles in the removal area.

We speculated that the changes in the dispersal rate at the 
Table 2. Percent swift fox females and social units producing a litter of pups in the removal and nonremoval areas, Piñon Canyon Maneuver Site, Colorado, USA, 1999-2000.

\begin{tabular}{ccccccc}
\hline & \multicolumn{2}{c}{ Removal area } & & \multicolumn{2}{c}{ Nonremoval area } \\
\cline { 2 - 3 } \cline { 5 - 6 } Yr & \% of $\mathbf{F}$ & \% of social units & & \% of $\mathbf{F}$ & \% of social units \\
\hline \multirow{2}{*}{1999} & 87.5 & 88.2 & & 83.3 & 90.0 \\
2000 & 43.8 & 46.7 & & 66.7 & 70.0 \\
\hline
\end{tabular}

end of the dispersal season may have coincided with changes in the survival rate and may explain some of the similarity in survival and dispersal rates at season's ends between the areas; hence, we assessed the risk of dispersing. Until October, we could determine parentage with certainty. Past October, however, we assumed dispersal to be at a peak and we could not determine parentage with certainty. By October, we radiocollared 27 juvenile foxes in the removal area and 8 in the nonremoval area. Of those, 9 were known to have finished dispersing by the end of the year within or from the removal area and 1 in or from the nonremoval area, with 6 and 0 dying during dispersal, respectively. Of the philopatric juveniles, 4 died in the removal area, and 2 died in the nonremoval area. The proportion of juveniles that dispersed was independent of area $\left(\chi^{2}=1.31, \mathrm{df}=1, P=\right.$ 0.252). The proportion of juvenile dispersers that died was also independent of area $\left(\chi^{2}=1.67, \mathrm{df}=1, P=0.197\right)$, but sample size was small in the nonremoval area. However, overall juvenile survival was dependent on dispersal strategy (decision to leave natal range vs. philopatry; $\chi^{2}=4.12$, $\mathrm{df}=$ $1, P=0.043)$. Dispersal often resulted in death for juveniles. Given all juvenile dispersers, of 8 juveniles that dispersed from the removal to nonremoval area, as previously mentioned, 5 died as a result of dispersing into the nonremoval area. In the removal area, survival was similarly dependent on dispersal strategy $\left(\chi^{2}=5.08, \mathrm{df}=1, P=\right.$ $0.024)$. Juveniles that dispersed from the removal area into the nonremoval area often died. Therefore, increasing juvenile survival rates apparently forced increased dispersal rates, with dispersal into nonremoval areas resulting in higher mortality. Thus, juvenile survival and dispersal rates were equalized between the areas by the end of the dispersal season.

Among dispersing foxes, 60.5\% (13 removal:10 nonremoval) successfully set up a new home range. Of those that established a new home range, 73.9\% (11 removal:6 nonremoval) paired with a mate. When we assessed dispersal outcome (specifically survival) between treatment areas and ages, all adults survived as a result of dispersing regardless of area, but survival may be dependent on area for dispersing juveniles $\left(\chi^{2}=3.34, \mathrm{df}=1, P=0.068\right)$. Analyzing the nonremoval area alone, all foxes survived after dispersal regardless of age, whereas in the removal area, age was a significant factor $\left(\chi^{2}=7.89, \mathrm{df}=1, P=0.005\right)$. Juveniles died as a result of dispersing more often than their adult counterparts, but that was true only for those in or leaving the removal area.
Table 3. Multi-way analysis of variance examining the influence of area and year on swift fox litter size, Piñon Canyon Maneuver Site, Colorado, USA, 1999-2000.

\begin{tabular}{lrrc}
\hline \multicolumn{1}{c}{ Source } & df & $\boldsymbol{F}$ & $\boldsymbol{P}$ \\
\hline Area $^{\mathrm{a}}$ & 1 & 0.332 & 0.567 \\
Yr $^{\mathrm{b}}$ & 1 & 7.313 & 0.010 \\
Area $\times$ yr & 1 & 1.196 & 0.280 \\
Error & 47 & & \\
\hline
\end{tabular}

a Removal, nonremoval.

b 1999, 2000.

\section{Reproduction}

We did not observe an increase in reproductive success with coyote removal. The number of females or social units producing a litter of pups declined from 1999 to 2000 (Table 2). However, reproduction by social units did not differ between the treatment areas in $1999\left(\chi^{2}=0.02\right.$, $\mathrm{df}=1, P=0.888)$ or $2000\left(\chi^{2}=1.33, \mathrm{df}=1, P=0.250\right)$. Overall litter size was $2.5 \pm 1.9$ pups ( $n=51$ litters). Mean litter size was significantly different between 1999 with 3.2 \pm 1.8 ( $n=27$ litters) and 2000 with $1.8 \pm 1.7$ pups $(n=24$ litters; $t=3.05, \mathrm{df}=49, P=0.004)$. Mean litter sizes for the nonremoval area were $2.3 \pm 1.5$ pups $(n=20$ litters $)$ and for the removal area $2.7 \pm 2.1$ pups ( $n=30$ litters). A multiway ANOVA showed that year, but not treatment area, contributed to differences in litter sizes (Table 3).

\section{Population Estimates}

Swift fox density did not increase with the changes in survival and dispersal as a result of coyote removal. We classified 169 different social units for all seasons combined: 97 in the removal area and 72 in the nonremoval area. Mean seasonal density was $0.26 \pm 0.18$ foxes $/ \mathrm{km}^{2}$ for the entire study area. Mean density varied seasonally with $0.16 \pm$ $0.05,0.42 \pm 0.22$, and $0.19 \pm 0.09$ foxes $/ \mathrm{km}^{2}$ during the breeding and gestation, pup-rearing, and dispersal seasons, respectively. By year, densities were $0.31 \pm 0.21$ foxes $/ \mathrm{km}^{2}$ in 1999 , and $0.20 \pm 0.14$ foxes $/ \mathrm{km}^{2}$ in 2000 . Overall mean densities were similar with $0.23 \pm 0.18$ and $0.30 \pm 0.18$ foxes $/ \mathrm{km}^{2}$ in the removal and nonremoval areas, respectively $(t=-0.93, \mathrm{df}=28, P=0.361)$. A multi-way ANOVA determined that mainly season and year influenced fox density estimates (Table 4). A lack of differences between the treatment areas indicated coyote removal did not affect swift fox density as density fluctuated seasonally similarly in both areas (Fig. 3A).

We used mark-recapture estimates to determine population size as a second measure of swift fox population response to coyote removal. During fox trapping surveys, we did not recapture any animals during 2 trapping sessions; thus, we could not calculate mark-recapture population estimates. A multi-way ANOVA indicated that year significantly influenced mark-recapture estimates $\left(F_{1,15}=\right.$ 17.083, $P=0.001)$; treatment area $\left(F_{1,15}=0.235, P=0.635\right)$ and season $\left(F_{2,15}=0.596, P=0.564\right)$ were not significant variables. A subsequent $t$-test indicated that the years had significantly different fox population estimates $(t=4.40, \mathrm{df}$ 
Table 4. Multi-way analysis of variance examining the influence of area, season, and year on swift fox density estimates, Piñon Canyon Maneuver Site, Colorado, USA, 1999-2000.

\begin{tabular}{lccc}
\hline \multicolumn{1}{c}{ Source } & df & $\boldsymbol{F}$ & $\boldsymbol{P}$ \\
\hline Area $^{\mathrm{a}}$ & 1 & 1.600 & 0.222 \\
Season $^{\mathrm{b}}$ & 2 & 11.572 & 0.001 \\
Yr $^{\mathrm{c}}$ & 1 & 4.677 & 0.044 \\
Area $\times$ season & 2 & 0.599 & 0.560 \\
Area $\times$ yr & 1 & 0.002 & 0.966 \\
Season $\times$ yr & 2 & 2.831 & 0.085 \\
Area $\times$ season $\times$ yr & 2 & 0.170 & 0.845 \\
Error & 18 & & \\
\hline
\end{tabular}

${ }^{a}$ Removal, nonremoval.

${ }^{\mathrm{b}}$ Breeding and gestation, pup rearing, dispersal.

c 1999, 2000.

$=18, P<0.001) ;$ mean fox estimates were $19.6 \pm 8.1(n=$ $7)$ in 1999 and $8.1 \pm 3.7(n=13)$ in 2000. Mark-recapture estimates (Fig. 3B) were similar to the density estimates (Fig. 3A), supporting the finding there was no change in overall population size of swift foxes following coyote removal.

\section{DISCUSSION}

From this experimental manipulation, we found that the greatest effect of coyote removal was increased and prolonged survival of juvenile swift foxes in the removal area, especially following the removal sessions. However, by the end of the dispersal seasons, juvenile survival rates were similar between the removal and nonremoval areas. Likely coyotes immigrated quickly into the removal area during their own dispersal season (Knowlton 1972, Gese 2005) and juvenile foxes dispersed into areas where coyotes were still prevalent. Although there was an increased risk of death associated with dispersal from the removal area, increasing juvenile survival and allowing them to reach new areas and breed can be important management and conservation goals. A slight increase in our adult survival rates appeared to occur in the removal area and was most notable in the dispersal seasons, which allowed the adults to reach the breeding season. Kamler et al. (2003a) reported no statistical difference in annual swift fox survival in an area after coyote reductions, although survival was $34 \%$ higher the year following reductions.

Although survival rates changed with coyote removal,
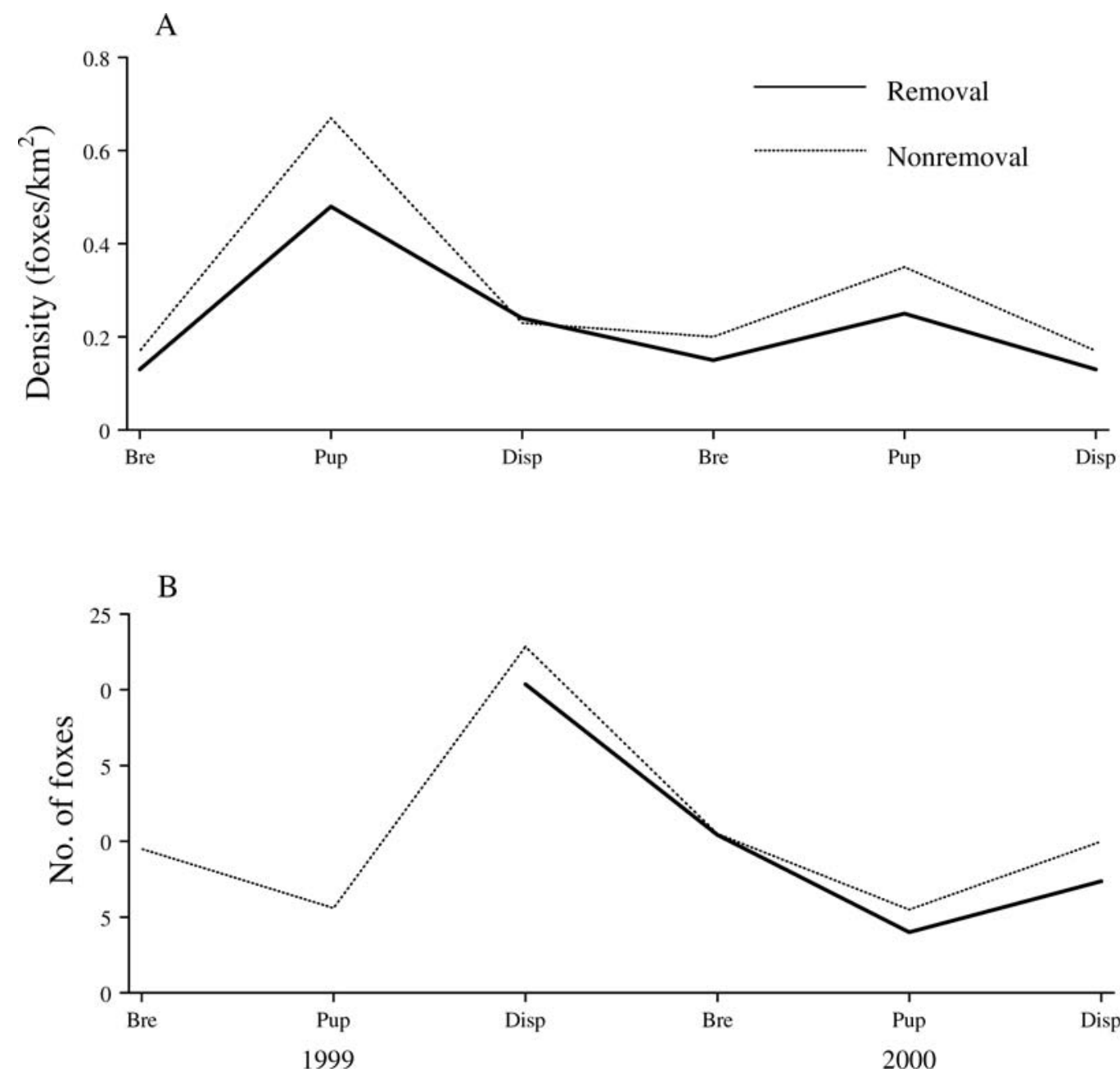

Figure 3. Estimates of swift fox (A) density, and (B) population size, within the removal and nonremoval areas during 6 biological seasons, Piñon Canyon Maneuver Site, Colorado, USA, 1999-2000. Bre = breeding and gestation; Pup = pup-rearing; and Disp = dispersal. 
decreased coyote density did not necessarily change the suite of overall mortality factors. Predation was delayed for juveniles in the removal area. However, predation was still the major cause of mortality in both areas for adults and juveniles alike, and was caused primarily by coyotes. This supports Cypher and Scrivner (1992), who reported that the proportion of kit fox deaths due to coyotes did not decrease with coyote removal. In contrast, Kamler et al. (2003a) had fewer deaths from coyote predation after removals.

Other causes of swift fox mortality are unlikely to compensate for coyote predation, at least on the PCMS. In terms of mesopredator release, repeated removals of coyotes could also change the abundance of other predators on swift foxes. Ralls and White (1995) and White et al. (2000) suggested red foxes pose a new and even worse threat to kit foxes than coyotes. Carbyn (1998) and Sovada et al. (1998) speculated red foxes could pose a similar threat to swift foxes. On our study area, red foxes do not occur and the other potential mammalian predators (i.e., bobcats [Lynx rufus], badgers [Taxidea taxus], and mountain lions [Felis concolor]) have different habitat and food requirements and were unlikely to have compensated for coyotes as the leading cause of predation on swift foxes.

With the increase in survival rates of juvenile foxes following coyote removal, we documented a change in juvenile dispersal-rate patterns. With fewer coyotes in the removal area, several scenarios could occur with regard to dispersal. Dispersal rates could decrease (i.e., be delayed) because food may be more plentiful due to a decrease in competition from coyotes or dispersal could increase because the area or individual home ranges can only support a limited number of foxes or because of reduced risk of predation from coyotes. Our results support the latter hypothesis. Juvenile foxes dispersed at a higher rate and earlier in the coyote removal area. With the increase in juvenile survival rate in the coyote removal area, juvenile foxes may have dispersed due to factors such as food limitations within the social unit and spatial saturation within the removal area. However, this increase and shift in dispersal was risky in terms of survival. Juvenile survival during dispersal was very low and philopatry was actually more favorable in terms of survival, especially leaving the removal area. The increase in juvenile survival rates appeared to force increased dispersal and earlier movements into nonremoval areas where juveniles were frequently killed by coyotes.

Juvenile foxes that delayed dispersal usually dispersed the following spring when birth of the new litter of pups apparently forced them to disperse because of resource limitations and social intolerance. This was evident with the increase of dispersal seen in the adult cohort due to the increase in overall juvenile survival. We suspect animals that dispersed later in the year in the removal area successfully dispersed during the following pup-rearing season as adults because fewer coyotes were likely encountered following the spring removal of coyotes. In the nonremoval area, adults did not disperse as frequently probably because they were taking over the range of a dead resident fox. Therefore, dispersal rates appeared to be more intraspecific densitydependent, probably related to social structure and tolerance, and indirectly related to changes in coyote density. Yet, increased dispersal in response to increased juvenile survival may be an important component in areas without population saturation where dispersing foxes may colonize new areas and assist in population recovery.

Coyote removal did not influence reproductive parameters in the swift fox population. With increased survival, not only should there be more foxes available for mating opportunities, but food could also be more plentiful due to less competition with coyotes allowing for an increase in percentage of females breeding or litter size. However, we did not document an increase in fox reproductive success or litter size. Instead, the percent of social units with litters and litter size depended on the year and decreased from 1999 to 2000 in both areas; cause of the decline is unknown.

Overall, coyote removal did not bring about a numerical increase in the swift fox population. Conversely, Kamler et al. (2003a) found increases in autumn swift fox density and relative abundance after coyote removal. However, the difference between the study sites in Texas and Colorado needs clarification. In northwestern Texas, swift foxes spatially avoided coyotes and did not den in coyote home ranges (Kamler et al. 2003b). Therefore, when coyotes were removed in northwestern Texas, vacancies for swift foxes became available as these areas were favorable habitat and became occupied by foxes following coyote removal (Kamler et al. 2003a, b). In contrast, on our study site in Colorado, coyote and fox home ranges overlapped extensively (Kitchen et al. 1999) and, therefore, removing coyotes would not create vacant habitat for swift foxes to occupy.

Our results could be questioned on the basis that the level of coyote removal was insufficient. However, removing 50$60 \%$ of a carnivore population is considered to be a high rate of removal (Connolly 1978, Harris and Saunders 1993). Our coyote removal was effective with a $\geq 50 \%$ reduction in the coyote population achieved over a short-term time scale based upon the percent of radiocollared coyotes removed from the study area $(60 \%)$ and percentages removed based on group size, density, and removal area size (40-75\%). Even with a $50-60 \%$ removal of coyotes, these short-term reductions of the coyote population changed swift fox demographics (i.e., survival, dispersal) on our study area. In Texas, Kamler et al. (2003a) estimated they reduced a coyote population by $56 \%$ and similarly changed swift fox demographics. Therefore, a high annual reduction in coyotes is needed to have an effect on swift fox demographics. If long-term effects on swift foxes are to occur, a severe decline in the coyote population is required and it must be sustained. Removal of coyotes over a larger area may also prolong the effect by minimizing or delaying recolonization of the vacant coyote territories. Yet, if the decision to remove coyotes is abandoned, a coyote population would recover quickly (Connolly 1978, Gese 2005). 
In our study, late-summer coyote removals appeared to be most effective for increasing adult and juvenile swift fox survival by reducing contact between the 2 predators during times of increased movements. Although spring removals decreased the number of resident coyotes in summer, they did not increase adult swift fox survival rates likely due to decreased movements during late breeding and gestation periods resulting in low encounter rates. As the pup-rearing season progressed, either enough coyotes immigrated into the removal area, or increased movements by foxes put them at risk, producing survival rates similar to those in the nonremoval area. However, short-term increases in fox survival (especially juv) by coyote removal may be important in areas where fox survival is low (especially during dispersal season) and might allow for increased breeding success, rearing of pups, and range expansion as demonstrated in Texas where there was vacant habitat available for swift foxes following coyote removal (Kamler et al. 2003a).

Given that there were annual and seasonal effects (but not treatment area effects) on reproduction and fox densities, results indicated that the swift fox population was regulated by intraspecific density-dependent factors. Changes in prey abundance likely drove the annual and seasonal changes in fox reproduction and density (Schauster et al. 2002a). The lack of change in swift fox density, even with changes in survival rates, indicated the swift fox population was likely at carrying capacity; all suitable habitat appeared to be occupied. Swift fox density was likely determined by resource abundance and reproduction as mediated through social tolerance, similar to other canid species. Coyote predation appeared to be compensatory with dispersal. Removing coyotes did increase fox survival in a top-down manner. However, habitat saturation and compensatory dispersal indicated a stronger role of bottom-up forces. This is not to say different results would not occur at different times, densities, or circumstances either on this study area or in other areas. Kamler et al. (2003a) suggested heavy coyote predation can suppress a swift fox population, yet a sink population can be changed relatively quickly, at least temporarily, to a source population following coyote reductions.

\section{MANAGEMENT IMPLICATIONS}

Our results indicate that although reducing coyote density did not increase swift fox population size on our study site, removal did temporarily increase swift fox survival directly, increase dispersal indirectly, and has the potential to affect swift fox density indirectly. We emphasize that these results are contingent on initial fox density, coyote density, and prey abundance, because different areas may yield different results as demonstrated by Kamler et al. (2003a). Although coyote removal might be a potential tool within certain areas and under special circumstances, coyote removal is expensive, controversial, short-term, and local in its effects. Removal would also likely need to be intense, sustained, and cover a larger area to reach levels effective for swift fox protection and population enhancement. For range-wide conservation, available habitat for swift fox colonization may be more important. Thus, initial research of the system may be necessary and goals must be clearly defined with an understanding of the possible results before any coyote control effort is deemed appropriate or necessary for population enhancement of swift foxes. We suggest management strategies also focus on prey and vegetation relationships, disturbance regimes, and requirements for a viable population (White and Garrott 1999, Kamler et al. 2003a, b; Thompson and Gese 2007).

\section{ACKNOWLEDGMENTS}

Financial and logistical support provided by the United States Army, Directorate of Environmental Compliance and Management, Fort Carson, Colorado, through the United States Fish and Wildlife Service, Colorado Fish and Wildlife Assistance Office, Lakewood, Colorado, and the Utah Cooperative Fish and Wildlife Research Unit, Utah State University, Logan, Utah. Additional support provided by the United States Department of Agriculture, Wildlife Services, National Wildlife Research Center, Logan Field Station at Utah State University, Logan, Utah. We thank J. A. Bissonette, J. Bowman, F. F. Knowlton, F. D. Provenza, and 2 anonymous referees for review of the manuscript. We thank Miller Aero Services, Inc., Boise City, Oklahoma, for aerial helicopter flying. We thank A. M. Kitchen and E. R. Schauster for initial capture of many foxes used in the study, P. A. Terletzky for computer assistance, T. Warren, R. Bunn, and B. Rosenlund for logistical assistance, and technicians E. Bergman, K. Bly, J. Bolis, S. Hahn, K. Hansen, E. Joyce, J. King, S. Lupis, J. Milner, L. Schutte, J. Webber, M. Wedermyer, B. Wirchansky, and T. Young for field assistance.

\section{LITERATURE CITED}

Andelt, W. F. 1987. Coyote predation. Pages 128-140 in M. Novak, J. A. Baker, M. E. Obbard, and B. Malloch, editors. Wild furbearer management and conservation in North America. The Ontario Trappers Association and the Ontario Ministry of Natural Resources, Ottawa, Canada.

Arthur, L. M. 1981. Coyote control: the public response. Journal of Range Management 34:14-15.

Bekoff, M., and E. M. Gese. 2003. Coyote (Canis latrans). Pages 467-481 in G. A. Feldhamer, B. C. Thompson, and J. A. Chapman, editors. Wild mammals of North America: biology, management, and conservation. Second edition. Johns Hopkins University Press, Baltimore, Maryland, USA.

Carbyn, L. N. 1998. Updated COSEWIC status report: swift fox, Vulpes velox. Committee on the Status of Endangered Wildlife in Canada, Canadian Wildlife Service, Ottawa, Ontario, Canada.

Connolly, G. E. 1978. Predator control and coyote populations: a review of simulation models. Pages 327-345 in M. Bekoff, editor. Coyotes: biology, behavior, and management. Academic Press, New York, New York, USA.

Covell, D. F. 1992. Ecology of the swift fox (Vulpes velox) in southeastern Colorado. Thesis, University of Wisconsin, Madison, USA.

Cutter, W. L. 1958. Denning of the swift fox in northern Texas. Journal of Mammalogy 39:70-74.

Cypher, B. L., and J. H. Scrivner. 1992. Coyote control to protect endangered San Joaquin kit foxes at the Naval Petroleum Reserves, California. Proceedings of the Vertebrate Pest Conference 15:42-47.

Disney, M., and L. K. Spiegel. 1992. Sources and rates of San Joaquin kit 
fox mortality in western Kern County, California. Transactions of the Western Section of the Wildlife Society 28:73-82.

Egoscue, H. J. 1979. Vulpes velox. Mammalian species. American Society of Mammalogists 122:1-5.

Fuller, T. K. 1989. Population dynamics of wolves in north-central Minnesota. Wildlife Monographs 105.

Fuller, T. K., and L. B. Keith. 1981. Non-overlapping ranges of coyotes and wolves in northeastern Alberta. Journal of Mammalogy 62:403-405.

Gese, E. M. 2005. Demographic and spatial responses of coyotes to changes in food and exploitation. Wildlife Damage Management Conference 11: 271-285.

Gese, E. M., D. E. Andersen, and O. J. Rongstad. 1990. Determining home-range size of resident coyotes from point and sequential locations. Journal of Wildlife Management 54:501-506.

Gese, E. M., O. J. Rongstad, and W. R. Mytton. 1988. Relationship between coyote group size and diet in southeastern Colorado. Journal of Wildlife Management 52:647-653.

Gese, E. M., O. J. Rongstad, and W. R. Mytton. 1989a. Population dynamics of coyotes in southeastern Colorado. Journal of Wildlife Management 53:174-181.

Gese, E. M., O. J. Rongstad, and W. R. Mytton. 1989b. Changes in coyote movements due to military activity. Journal of Wildlife Management 53: 334-339.

Harris, S., and G. Saunders. 1993. The control of canid populations. Symposium of the Zoological Society of London 65:441-464.

Harrison, D. J., J. A. Bissonette, and J. A. Sherburne. 1989. Spatial relationships between coyotes and red foxes in eastern Maine. Journal of Wildlife Management 53:181-185.

Heisey, D. M., and T. K. Fuller. 1985. Evaluation of survival and causespecific mortality rates using telemetry data. Journal of Wildlife Management 49:668-674.

Henke, S. E., and F. C. Bryant. 1999. Effects of coyote removal on the faunal community in western Texas. Journal of Wildlife Management 63: 1066-1081.

Hillman, C. N., and J. C. Sharps. 1978. Return of swift fox to northern Great Plains. Proceedings of the South Dakota Academy of Science 57: 154-162.

Holt, R. D., and G. A. Polis. 1997. A theoretical framework for intraguild predation. American Naturalist 149:745-764.

Johnson, W. E., T. K. Fuller, and W. L. Franklin. 1996. Sympatry in canids: a review and assessment. Pages 189-218 in J. L. Gittleman, editor. Carnivore behavior, ecology, and evolution. Volume 2. Cornell University Press, Ithaca, New York, USA.

Kamler, J. F., W. B. Ballard, R. L. Gilliland, P. R. Lemons, and K. Mote. 2003a. Impacts of coyotes on swift foxes in northwestern Texas. Journal of Wildlife Management 67:317-323.

Kamler, J. F., W. B. Ballard, R. L. Gilliland, and K. Mote. 2003b. Spatial relationships between swift foxes and coyotes in northwestern Texas. Canadian Journal of Zoology 81:168-172.

Kie, J. G., J. A. Baldwin, and C. J. Evans. 1996. CALHOME: a program for estimating animal home ranges. Wildlife Society Bulletin 24:342-344.

Kilgore, D. L., Jr. 1969 An ecological study of the swift fox (Vulpes velox) in the Oklahoma Panhandle. American Midland Naturalist 81:512-534.

Kitchen, A. M., E. M. Gese, and E. R. Schauster. 1999. Resource partitioning between coyotes and swift foxes: space, time, and diet. Canadian Journal of Zoology 77:1645-1656.

Kitchen, A. M., E. M. Gese, and E. R. Schauster. 2000. Changes in coyote activity patterns due to reduced exposure to human persecution. Canadian Journal of Zoology 78:853-857.

Knowlton, F. F. 1972. Preliminary interpretations of coyote population mechanics with some management implications. Journal of Wildlife Management 36:369-382.

Kozlowski, A. J., T. J. Bennett, E. M. Gese, and W. M. Arjo. 2003. Live capture of denning mammals using an improved box trap enclosure: kit foxes as a test case. Wildlife Society Bulletin 31:630-633.

Murray, D. L. 2006. On improving telemetry-based survival estimation. Journal of Wildlife Management 70:1530-1543.

Otis, D. L., and G. C. White. 1999. Autocorrelation of location estimates and the analysis of radiotracking data. Journal of Wildlife Management 63:1039-1044.

Pollock, K. H., S. R. Winterstein, C. M. Bunck, and P. D. Curtis. 1989.
Survival analysis in telemetry studies: the staggered entry approach. Journal of Wildlife Management 53:7-15.

Ralls, K., and P. J. White. 1995. Predation on San Joaquin kit foxes by larger canids. Journal of Mammalogy 76:723-729.

Sacks, B. N., K. M. Blejwas, and M. M. Jaeger. 1999. Relative vulnerability of coyotes to removal methods on a northern California ranch. Journal of Wildlife Management 63:939-949.

Sargeant, A. B., S. H. Allen, and J. O. Hastings. 1987. Spatial relations between sympatric coyotes and red foxes in North Dakota. Journal of Wildlife Management 51:285-293.

Schauster, E. R., E. M. Gese, and A. M. Kitchen. 2002a. Population ecology of swift foxes (Vulpes velox) in southeastern Colorado. Canadian Journal of Zoology 80:307-319.

Schauster, E. R., E. M. Gese, and A. M. Kitchen. 2002b. An evaluation of survey methods for monitoring swift fox abundance. Wildlife Society Bulletin 30:464-477.

Schnabel, Z. E. 1938. The estimation of the total fish population of a lake. American Mathematicians Monthly 45:348-352.

Scott-Brown, J. M., S. Herrero, and J. Reynolds. 1987. Swift fox. Pages 432-441 in M. Novak, J. A. Baker, M. E. Obbard, and B. Malloch, editors. Wild furbearer management and conservation in North America. The Ontario Trappers Association and the Ontario Ministry of Natural Resources, Ottawa, Canada.

Scrivner, J. H., T. P. O’Farrell, and T. T. Kato. 1987. Dispersal of San Joaquin kit foxes, Vulpes macrotis mutica, on Naval Petroleum Reserve No. 1, Kern County, California. U.S. Department of Energy Topical Report, EG\&G/EM Santa Barbara Operations Report No. EGG 10282-2190, Washington, D.C., USA.

Shaw, R. B., and V. E. Diersing. 1990. Tracked vehicle impacts on vegetation at the Pinon Canyon Maneuver Site, Colorado. Journal of Environmental Quality 19:234-243.

Sovada, M. A., C. C. Roy, J. B. Bright, and J. R. Gillis. 1998. Causes and rates of mortality of swift foxes in western Kansas. Journal of Wildlife Management 62:1300-1306.

Swihart, R. K., and N. A. Slade. 1985. Influence of sampling interval on estimates of home-range size. Journal of Wildlife Management 49:10191025.

Terborgh, J., J. A. Estes, P. Paquet, K. Ralls, D. Boyd-Heger, B. J. Miller, and R. F. Noss. 1999. The role of top carnivores in regulating terrestrial ecosystems. Pages 39-64 in M. Soule and J. Terborgh, editors. Continental conservation: scientific foundations of regional reserve networks. Island Press, Washington, D.C., USA.

Theberge, J. B., and C. H. R. Wedeles. 1989. Prey selection and habitat partitioning in sympatric coyote and red fox populations, southwest Yukon. Canadian Journal of Zoology 67:1285-1290.

Thompson, C. M., and E. M. Gese. 2007. Food webs and intraguild predation: community interactions of a native mesocarnivore. Ecology 88: 334-346.

Thurber, J. M., R. O. Peterson, J. D. Woolington, and J. A. Vucetich. 1992. Coyote coexistence with wolves on the Kenai Peninsula, Alaska. Canadian Journal of Zoology 70:2494-2498.

Voigt, D. R., and W. E. Berg. 1987. Coyote. Pages 344-357 in M. Novak, J. A. Baker, M. E. Obbard, and B. Malloch, editors. Wild furbearer management and conservation in North America. The Ontario Trappers Association and the Ontario Ministry of Natural Resources, Ottawa, Canada.

Voigt, D. R., and B. D. Earle. 1983. Avoidance of coyotes by red fox families. Journal of Wildlife Management 47:852-857.

von Schantz, T. 1984. 'Non-breeders' in the red fox Vulpes vulpes: a case of resource surplus. Oikos 42:59-65.

Wagner, F. H. 1975. The predator-control scene as of 1974. Journal of Range Management 28:4-10.

White, G. C., and R. A. Garrott. 1990. Analysis of radio-tracking data. Academic Press, New York, New York, USA.

White, P. J., W. H. Berry, J. J. Eliason, and M. T. Hanson. 2000. Catastrophic decrease in an isolated population of kit foxes. Southwestern Naturalist 45:204-211.

White, P. J., and R. A. Garrott. 1999. Population dynamics of kit foxes. Canadian Journal of Zoology 77:486-493.

White, P. J., and K. Ralls. 1993. Reproduction and spacing patterns of kit foxes relative to changing prey availability. Journal of Wildlife Management 57:861-867. 
White, P. J., K. Ralls, and R. A. Garrott. 1994. Coyote-kit fox interactions as revealed by telemetry. Canadian Journal of Zoology 72:1831-1836.

Wilkinson, L., M. Hill, J. P. Welna, and G. K. Birdenbeuel. 1992. SYSTAT for Windows: statistics, version 5. SYSTAT, Evanston, Illinois, USA.

Winterstein, S. R., K. P. Pollock, and C. M. Bunck. 2001. Analysis of survival data from radiotelemetry studies. Pages 351-380 in J. J.
Millspaugh and J. M. Marzluff, editors. Radio tracking and animal populations. Academic Press, New York, New York, USA.

Worton, B. J. 1989. Kernel methods for estimating the utilization distribution in home-range studies. Ecology 70:164-168.

Associate Editor: Jeff Bowman. 